\title{
Material contribution, responsibility, and liability
}

In her inventive and tightly argued book Defensive Killing, ${ }^{1}$ Helen Frowe defends the view that bystanders - those who do not pose threats to others—cannot be liable to being harmed in self-defence or in defence of others. On her account, harming bystanders always infringes their rights against being harmed, since they have not acted in any way to forfeit them. According to Frowe, harming bystanders can be justified only when it constitutes a lesser evil. ${ }^{2}$ In this brief essay, I make the case that some bystanders can indeed be liable to harm. They can be liable, I will argue, because they can be morally responsible for threats of harm, and in becoming responsible they can forfeit their rights. While bystanders cannot be responsible for initiating threats, they can become responsible for the persistence of threats, and for culpably failing to prevent them from being initiated in the first place.

Permissible Killing and Liability

Central to Frowe's account of defensive killing is the distinction between threats and bystanders on the one hand, and between direct and indirect threats on the other. Direct and indirect threats of harm will, if that harm eventuates, have materially contributed to harm. Bystanders, on the other hand, are materially innocent $(24,37)$, regardlessaccording to Frowe - of their intentions or dispositions. Material innocence is defined in terms of causality: 'The materially innocent are those who are not noncentes: not causing harm' (24-5).

\footnotetext{
${ }^{1}$ Helen Frowe, Defensive Killing (Oxford: Oxford University Press, 2014). All in-text page references are to this work.

${ }^{2}$ She argues that there are significant restrictions on the use of such justification for harming bystanderswe must be willing to take on significant cost to ourselves to avoid harming bystanders: 'In cases where Victim will avert even very serious harm only to himself (or one other innocent person), my account will not permit him to inflict more than a moderate cost upon a bystander' (10).
} 
Whether and how an agent is on track to materially contribute to some harm is relevant to whether they can be harmed to prevent it, and whether they can be liable to such harm. To illustrate, consider four cases in which agents are present when some harm may befall a person (Vicky).

In Case 1 Dirk pushes a heavy cart downhill towards Vicky. Dirk poses a threat to Vicky. And the threat is direct, by Frowe's criteria, since (1) if the cart collides with Vicky and she dies from its impact, Dirk will have killed her; and (2) there is no intervening agency between his pushing of the cart and her death.

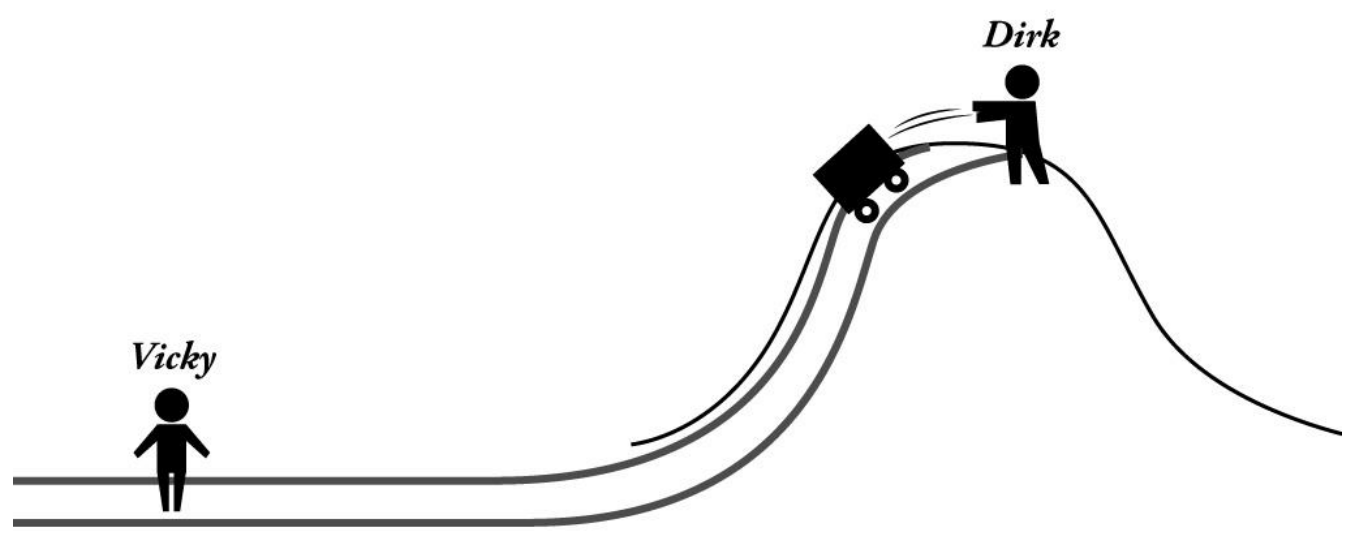

In Case 2, Ella removes a rock that would otherwise stop a cart that is hurtling downhill toward Vicky. Frowe does not discuss this sort of case. Hence, it is not entirely clear whether on her account the threat Ella poses counts as a direct or indirect threat. Ella acts in a way that will lead to Vicky's death, and there is no intervening agency between her removal of the rock and Vicky's death. But, unlike Dirk, she does not use 
something as a tool to kill Vicky. Does Ella kill Vicky or does she merely endanger her? Some may say that she does kill her, though others may resist and instead claim that her contribution to Vicky's death is that she allows or enables it to occur. It would be instructive to hear what Frowe thinks of agents who contribute to harm in this way, but since she does not focus on them, I will not discuss such cases at length.

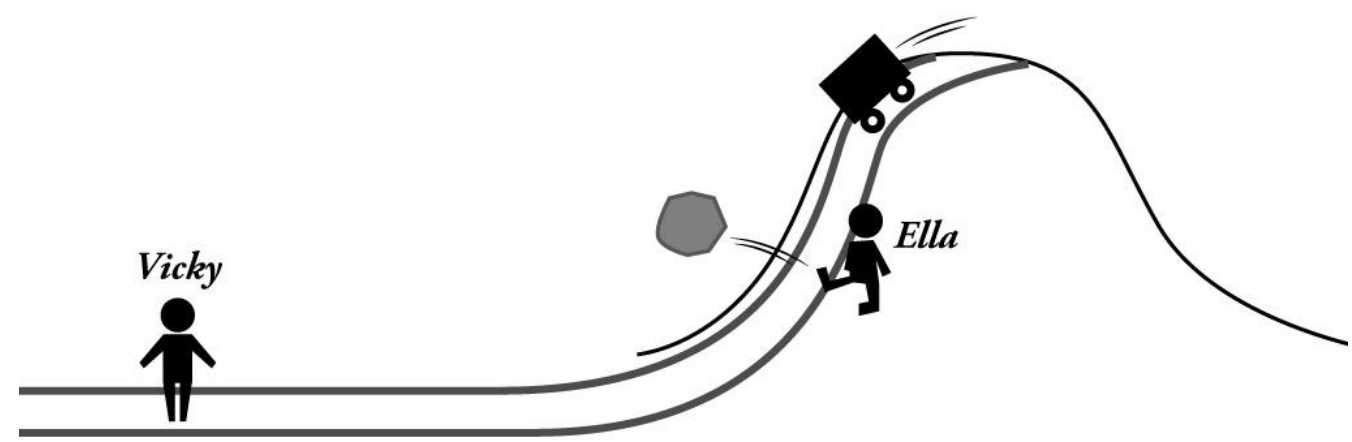

Then consider Case 3. Unlike Dirk and Ella, Ollie neither initiates the threat of the onrushing cart, nor removes an obstacle that would otherwise block it. However, by virtue of his location he prevents Vicky from escaping. One of the novel (and, to my mind, entirely convincing) aspects of Frowe's view is that she regards Ollie (the obstructor) as posing a threat, rather than as a mere bystander. She writes: 'it is a mistake to think that obstructors are bystanders' (22). In what sense does Ollie pose a threat? He poses a threat because his presence prevents Vicky's escape. Were he not present, she could avoid the cart without difficulty and without anyone being harmed. The threat that Ollie poses is indirect. If Vicky dies from the impact of the cart, Ollie will not have killed 
her, but he will have endangered her. And because of this, Ollie may be liable to being

killed by Vicky to save herself.

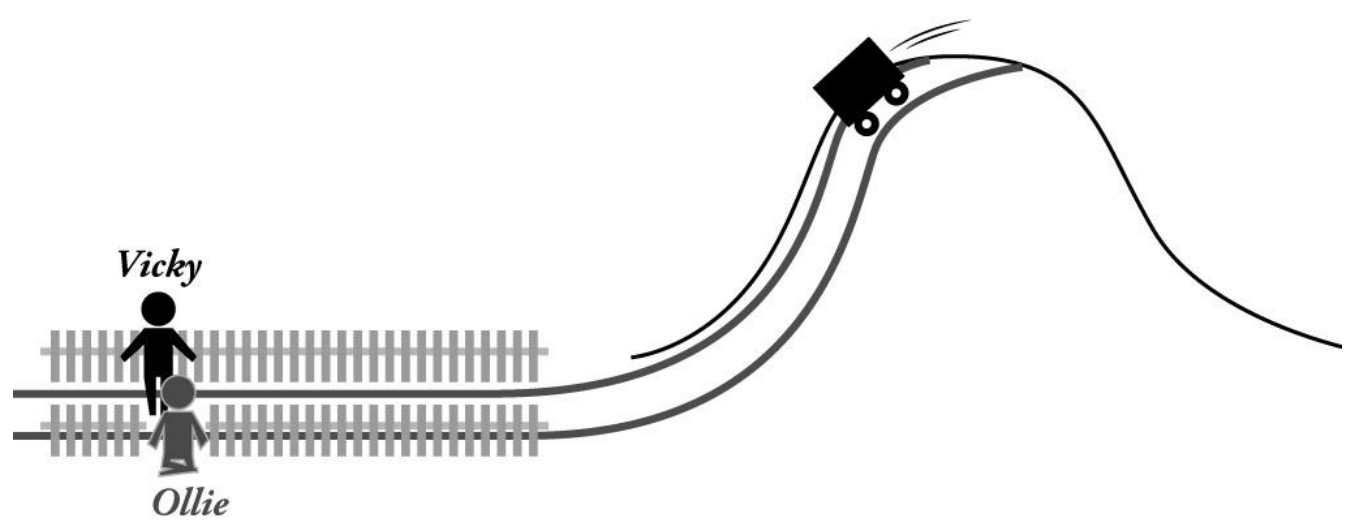

In Case 4, finally, Alice is standing on the side of a hill, where a cart is hurtling down towards Vicky. 


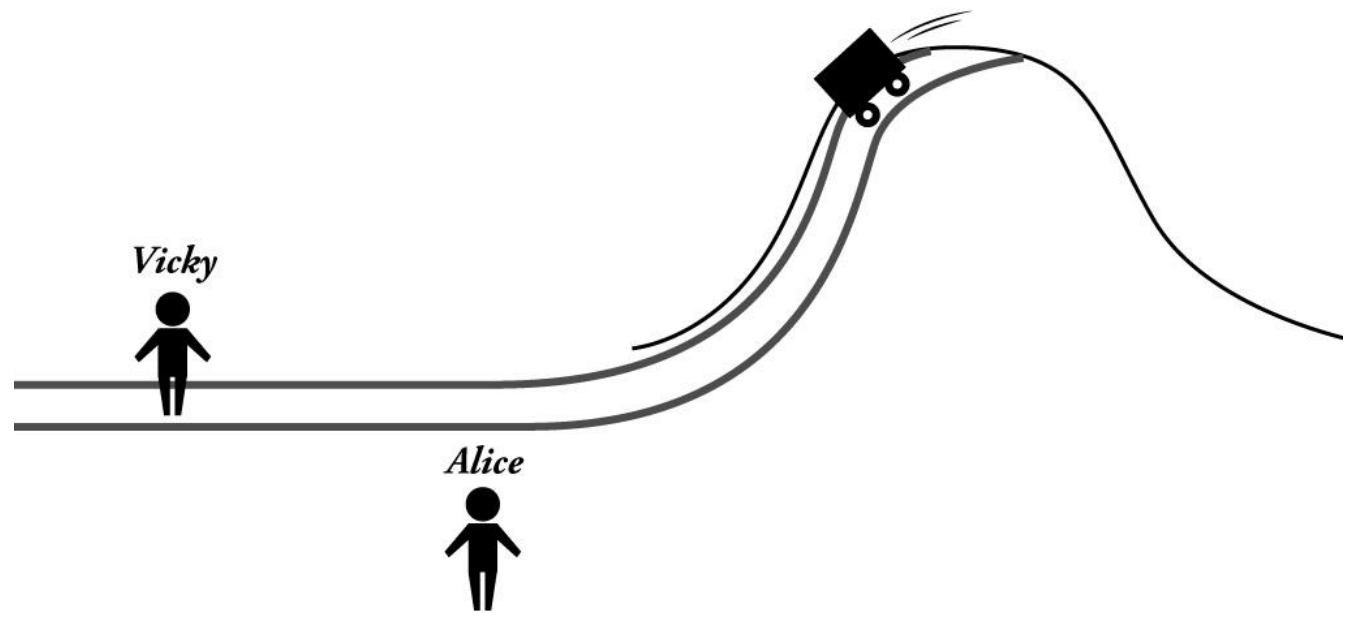

Responsibility

Frowe's distinctions between types of threats and between threats and bystanders are the first plank of her account of liability to harm and permissible killing. The second plank concerns the responsibility of those who pose threats. Whether Ollie, Ella and Dirk are liable to be killed, on her view, depends on their degree of responsibility for the threats that they pose.

Agents who are wholly non-responsible for threats cannot be liable to be killed or harmed in self-defence. An agent can be non-responsible for threats either because they did not exercise their agency at all in posing it—as when a person is thrown off a building and may fall on someone standing below_or because they have the reasonable belief that any opportunity to avoid posing a threat would entail a cost sufficiently high that they would not be required to bear it to protect the prospective victim (11). 
Some simple terminology may help to elucidate this second notion of nonresponsibility. Call the cost that a person has a responsibility to shoulder to prevent harm from befalling another the required cost, and whatever cost a person would in fact need to shoulder to do so the necessary cost. When an agent reasonably believes that the necessary cost of avoiding posing a threat to another exceeds the required cost of preventing the harm to which it may give rise, they are non-responsible for posing the threat. If, for example, I would have to lose a leg to avoid behaviour that would materially contribute to bruising your finger, I will be non-responsible for the threat of bruising your finger, insofar as I am not required to bear so high a cost to prevent this harm to you. If, on the other hand, I need only sustain a bruised finger to avoid initiating a threat that would cause you to lose your leg, I will be responsible for this threat.

The issues of material contribution and responsibility are not only relevant to assessments of liability to harm—-harming without infringing rights— but to permissible harming more generally. Frowe maintains that agents posing direct threats needn't be responsible for it to be permissible to kill them in self-defence (even though they are non-liable). So even if Dirk is non-responsible for the threat he poses, Vicky can nevertheless kill him in self-defence. Vicky cannot, however, kill indirect threats like Ollie to save herself if he is wholly non-responsible for the threat he poses, nor can she kill bystanders like Alice.

On Frowe's account, whether the necessary cost of refraining from posing a threat exceeds the required cost depends not only on the magnitude of the threat (the harm to which it will give rise), but its nature (74). Prospective direct threats, like Dirk, are required to bear more cost to avoid posing threats than prospective indirect threats like Ollie. Ollie is required to bear 'non-trivial' but not high costs to avoid posing the indirect threat to Vicky (74). The required cost of Dirk's avoiding pushing the cart down 
to Vicky is higher than the required cost of Ollie's refraining from sitting on the path where he knows he will obstruct Vicky's escape.

So far, we've been discussing the required cost of refraining from initiating a threat. Whether the required cost exceeds the necessary cost will determine whether an agent is responsible for initiating a threat. But we can also consider the question of required cost from a different angle: the required cost of intervening to prevent a threat resulting in harm. Suppose that these agents have already posed the threat (Dirk has pushed the cart, Ella has removed the rock, Ollie has sat down on the path). We can now ask how much cost they would be required to bear to prevent the cart from hitting Vicky, in case they could now intervene to do so? All else being equal, Frowe's view implies that Dirk is required to shoulder more cost to avert the threat than Ollie.

Whether the required cost of intervention exceeds the necessary cost will determine whether an agent is responsible for the persistence of the threat.

Finally, we can consider the notion of required cost from a third angle: enforcement. Here, we ask how much cost could be imposed upon the agents—in terms of preventing them from initiating a threat or compelling them not to allow it to persist - to stop their conduct from maturing into harm to Vicky, without wronging them. Here Frowe implies that, all else being equal, we could impose more cost on Dirk than on Ollie for these purposes. Agents who pose threats are not only responsible for them, but more or less culpable with respect to them. That is, there is a difference between someone who fails to take advantage of a reasonable opportunity to avoid posing a threat and one who intentionally does not do so- the latter person is liable to more harm than the former, relative to what is at stake (83). Consequently, a very culpable indirect threat may be liable to be killed in self-defence (25).

The distinction between initiating a threat and being relevant to its persistence suggests, I think, that agents can start out as non-responsible for threats they pose, but 
become responsible for them later. Suppose that Dirk initiates a threat involuntarily-he was pushed up against the cart and it consequently starts rolling downhill. Dirk is initially wholly non-responsible for the threat. But suppose Dirk now realizes that, with a minimum of effort, he can push a button next to him that will cause a fence to spring up in front of Vicky, stopping the cart from continuing downhill and protecting her from its impact. Suppose that for no good reason he fails to do this. In this case, it seems plausible that he becomes responsible for the persistence of the threat, even though he was non-responsible for its initiation. And it also seems that, while he may not have been liable to being harmed to protect Vicky as he was poised to initiate the threat, he now does seem liable to being harmed for his role in its persistence.

So too with Ollie. Suppose that he initially at $\mathrm{t}_{1}$ sits down on the spot where he blocks Vicky's escape. Imagine that at this point he is entirely innocent of the threat he poses to Vicky (he does not know, and could not reasonably be expected to know, that she is under threat by a cart on its way downhill.) Imagine that, shortly afterwards at $\mathrm{t}_{2}$, the situation becomes transparent to him; he is able to remove himself at very trivial cost from the spot where he is blocking Vicky's escape, but fails to do so. Here Ollie seems initially non-responsible for a threat, but becomes responsible because it persists due to his culpable failure to move. While he was not liable to being harmed to prevent him from occupying the place where he put Vicky under threat, he can become liable by failing to prevent the threat when he could do so at little cost.

Bystanders

So far, we've considered cases of people who, on Frowe's account, pose threats and thus can become material contributors to harm. Let's now return to Alice. Alice is not a threat. Her agency has played no role in initiating the threat to Vicky. Nor does Alice's 
presence prevent Vicky from escaping. (It is even, perhaps, good for Vicky that Alice is present on the scene, since she may offer the opportunity of avoiding the threat from maturing into harm.) Alice is a paradigmatic bystander, in Frowe's sense. The bystander/threat distinction is, for Frowe, non-moralised: "we can and ought to establish whether a person is a threat or a bystander independently of her moral innocence or responsibility" (24). What distinguishes bystanders is that they are materially innocent with respect to threats., Frowe defines the notion of material innocence in terms of causal relevance (24-5). Alice is materially innocent with respect to the threat Vicky faces because she plays no causal role in it. Frowe argues that bystanders like Alice, in addition to being materially innocent, cannot in any way be responsible for threats. Indeed, she writes, 'the idea of a responsible bystander is not only unattractive but conceptually incoherent' (28).

Culpable Bystanders and Responsibility

Frowe's arguments regarding the non-liability of bystanders rely on two premises. The first is that bystanders are 'materially' innocent, since they are not causing harm (24). The second is that, material innocence aside, they are not responsible for threats to victims. Frowe recognizes that bystanders can of course be culpable in various ways-they may harbour bad intentions or may even have made clumsy and inept attempts to harm people. The key, according to her, is that bystanders 'are not doing (nor have they done) anything with respect to the threat to Victim for which blame would be appropriate..... There is thus nothing with respect to the threat to Victim for which a bystander can be morally responsible.' (24) I'll consider each of these premises in turn.

\section{Material Innocence}


Are all bystanders materially innocent? To answer this we need to know whether bystanders like Alice can plausibly be regarded as causally relevant to harms that befall victims like Vicky. Here it is important to distinguish between two classes of people Frowe would regard as bystanders. Imagine the cart slams into Vicky, injuring her. In the first scenario, Alice not only played no role in initiating the threat, but was at no point in a position to prevent the threat from maturing into a harm (we could imagine that a high fence bars her from intervening to protect Vicky). Frowe's diagnosis of this sort of bystander seems entirely apt. There really is no way that Alice can or could have acted that will prevent the cart from crashing into Vicky. Consequently, the harm that befalls Vicky does not depend in any way on Alice's conduct. Suppose that the cart hits Vicky and we are asked how Alice was responsible for it. Here we can truly say that she was not relevant to it in virtue of either what she has done or what she has failed to do, since there was nothing she could do to prevent it. It makes no sense to say of such a bystander that she allowed the harm to occur-she just happened to be nearby when it took place. She was responsible neither for initiating the threat nor for its persistence. Let's turn to a second scenario. Like Alice, Abel played no role in initiating the threat-he was simply positioned on the hill nearby. 


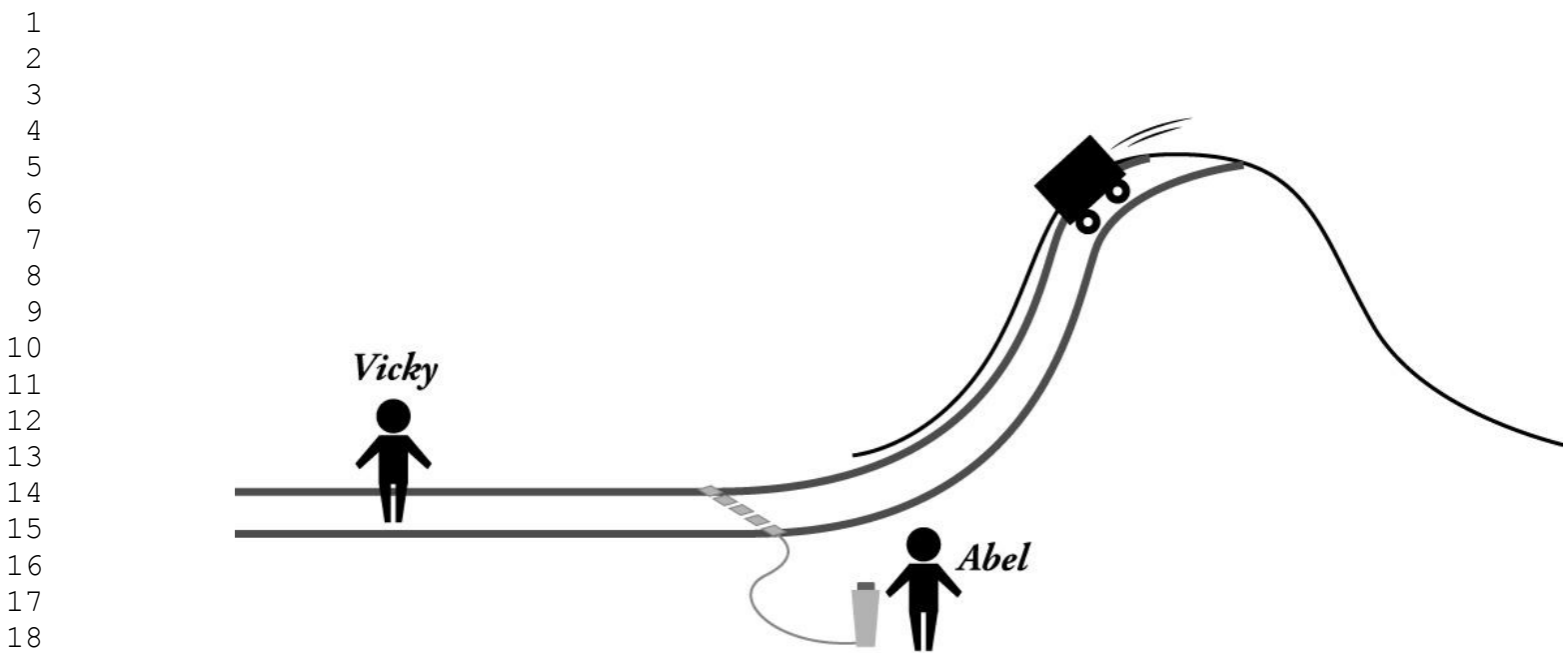

\begin{abstract}
Unlike Alice, however, Abel becomes aware that he can intervene, thereby preventing the threat from maturing into a harm (he spots a button nearby that he knows will trigger the protective fence to spring up, just like Dirk in our earlier example). If Abel then fails to press the button, he will have allowed harm to occur to Vicky. In this case the harm she suffers is counterfactually dependent on Abel's conduct. It depends not on what he did, but on what he could have but didn't do.

Frowe discusses a structurally similar case, Drowning Child.
\end{abstract}

\begin{abstract}
"Walker passes a lake on her morning stroll. Child is drowning in the lake.
Walker observes Child's predicament, and does nothing to help Child, even though she could easily save her. Child drowns." (29)
\end{abstract}

Frowe argues that, although Walker is culpable in this case, this is not because of her role as a bystander, given that she didn't contribute to the threat. Thus, she argues that Walker is not culpable qua bystander (indeed she could have saved the child while 
remaining a bystander). Rather, Walker is culpable because she violated a duty to save the child. (30) But whether or not bystanders like Abel and Walker should be characterized as culpable bystanders, the critical question is whether bystanders who fail to help others when they have a duty to do so should be considered materially innocent with respect to the harms they fail to prevent? Since, as we have seen, this is a question of causal relevance, our answer will depend on the account of causation we employ. According to many counterfactual accounts of causation, Abel will count as a cause of Vicky's death. Such accounts maintain that we can be causally responsible through our omissions as well as through our actions—a doctor's failure to treat a patient can cause the patient's death. ${ }^{3}$ As Jonathan Bennett has pointed out in discussion of a similar case, Abel's nonintervention is essential to completing the causally sufficient conditions for the cart's crashing into Vicky, given the description of the initial setup. ${ }^{4}$ The fact that he does not push the button is a crucial part of the story of why she is harmed, given his position on the hill and has capacity to prevent it. The same is true of Walker in Drowning Child.

Abel is not physically connected to Vicky. But on counterfactual accounts causes need not be physically linked to their effects. ${ }^{5}$ On such accounts, then, bystanders like Abel are not materially innocent of the harm that befalls Vicky, while bystanders like Alice are. Arguing against such a view, Frowe could claim that genuine causes are physically connected to their effects. Here the contrast between Dirk and Abel is clearDirk initiates a continuous causal sequence by transferring energy to the cart. He is linked to Vicky's injuries by a complete causal process. This process is a physical one-a

\footnotetext{
${ }^{3}$ Carolina Sartorio, 'Causation and Responsibility', Philosophy Compass 2 (5) (2007), pp. 749-65, at p. 753. ${ }^{4}$ Jonathan Bennett, The Act Itself (Oxford, Oxford University Press, 1995), p. 129.

${ }^{5}$ Jonathan Schaffer, 'Causes Need Not Be Physically Connected to Their Effects: The Case for Negative Causation', in Christopher Hitchcock (ed.), Contemporary Debates in Philosophy of Science (Oxford: Blackwell, 2004), pp. 197-216. See also David Lewis 'Void and Object', in J. Collins, N. Hall and L. A. Paul (eds), Causation and Counterfactuals (Cambridge, MA: MIT Press, 2004), pp. 277-90.
} 
complete energy momentum sequence connects Dirk's movement to the cart's collision with Vicky. ${ }^{6}$

Interesting variants of this approach have been developed in the causation literature. ${ }^{7}$ But there are also serious challenges to it. First, there are many other cases in which causes are not physically connected to their effects, but nevertheless seem to be genuine cases of causation. Ella, in our earlier example, is one such case. Ella is relevant to the harm to Vicky by removing something that will stop it. It would be very counterintuitive to deny that Ella is causally relevant to Vicky's death, even though there is no continuous casual sequence linking them. ${ }^{8}$ Further, we've seen that Frowe does regard Ollie as a threat and a material contributor to the harm that would befall Vicky. But Ollie is not physically connected to Vicky's death via a continuous casual sequence.

Let's assume, however, the view that causes must be physically connected to their effects. Bystanders like Abel, then, would be treated as causally non-responsible for harms that they allow. We can nevertheless maintain that, although Abel did not cause harm to Vicky, he failed to do something that would have causally prevented it from occurring. Following Carolina Sartorio, I'll call connections of this sort quasi-causal, and regard Abel as quasi-causally responsible for the harm to Vicky. ${ }^{9}$

The question then is why causal responsibility, as opposed to quasi-causal responsibility, should be the relevant condition for being regarded as potentially responsible for a threat. After all, we seem to attribute moral responsibility to many

\footnotetext{
${ }^{6}$ Ned Hall refers to this kind of causal connection as exhibiting 'locality': Ned Hall, 'Non-Locality on the Cheap? A New Problem for Counterfactual Analyses of Causation', Noûs 36, no. 2 (2002): 276-94; Ned Hall, 'Two Concepts of Causation', in J. Collins, N. Hall and L. A. Paul (eds), Causation and Counterfactuals (Cambridge, MA: MIT Press, 2004), 225-76.

7 Phil Dowe, 'Why Preventers and Omissions Are Not Causes', in Christopher Hitchcock (ed.), Contemporary Debates in Philosophy of Science (Oxford: Blackwell, 2004), pp.189-96, David Fair, 'Causation and the Flow of Energy', Erkenntnis 14 (1979), pp. 219-50.

${ }^{8}$ For detailed discussion, see Jonathan Schaffer, 'Causation by Disconnection'. Philosophy of Science 67 (2000), pp. 285-300.

${ }^{9}$ Sartorio, 'Causation and Responsibility', pp. 752-4.
} 
agents who are physically disconnected from their effects, whether or not we consider them causally responsible. We bear responsibility for the death of a friend's dog if we promised to feed it while they were away, but simply didn't show up; we bear responsibility for a person's death if we provide the wrong address to emergency services that seek to attend them. Why should quasi-causal responsibility be insufficient to make a person potentially responsible for a threat? Whether agents that are quasi-causally responsible for threats are responsible for them would depend on further factors, in particular whether the necessary cost of intervening to prevent harm exceeds the required cost, an issue to which I now turn. Either bystanders can be materially noninnocent with respect to threats of harm or material innocence is not a plausible condition for responsibility for threats.

\section{Non-responsibility}

How could Abel be responsible for the threat that Vicky faces? As Frowe rightly points out, 'not just any wrongdoing will render a person a morally responsible bystander whom Victim can permissibly kill' (27). If Abel has cheated on his spouse or harmed other people in the past, that does not make him responsible for the threat that Vicky now faces. In this case, he is certainly not responsible for initiating the threat.

It is worth pointing out, though, that there may be scenarios in which bystanders can be responsible, in some measure, for the initiation of the threat. Suppose Abel spots Dirk walking along at the top of the hill at $\mathrm{t}_{\text {1-x }}$. He realizes that Dirk is at risk of stumbling into the cart at $\mathrm{t}_{1}$ (he knows, though Dirk does not, that there is a soft patch of ground that he is likely to slip on). Abel knows that all he needs to do is to shout out to Dirk—'watch out for the soft spot!' — and he will not stumble into the cart and send it down towards Vicky. At $\mathrm{t}_{1-\mathrm{x}}$ the lethal threat of onrushing cart has not yet been initiated. 
If it is initiated at $t_{1}$, it will be because of Abel's culpable failure to warn Dirk at very little cost previously.

Then, too, Abel may be responsible for the threat insofar as he becomes responsible for its persistence. Just as Dirk, Ella or Ollie could be responsible for the threat in the cases discussed above, if there is a point at which, without taking on undue cost, Abel can intervene to prevent the threat from maturing into a harm and does not do so, he is responsible for the persistence of the threat. Suppose that he can prevent the cart from hitting Vicky by simply pressing the fence-erecting button in the interval between time $t_{1}$ and $t_{2}$, but he fails to do so. Assume that the situation is completely transparent to him. He is fully aware that the costs to him involved in preventing Vicky's death are negligible. In this case it seems plausible to regard Abel as bearing responsibility for the threat Vicky faces at time $t_{3}$. He is responsible because Vicky's predicament at $\mathrm{t}_{3}$ results in part from his earlier failure to take on cost that he was required to bear to protect her. Whereas at $\mathrm{t}_{1}$ Vicky's predicament does not depend in any way on Abel's failure to take on cost he was required to bear, this is the case at $\mathrm{t}_{3}$. So while it is true that Abel was not initially responsible for the threat posed to Vicky, he has become responsible for the persistence of the threat.

Abel is, in this respect, clearly quite different from other bystanders who engage in wrongdoing, such as those who may be cheating on their spouses or their tax returns (28). He wrongs Vicky by failing to prevent her from being harmed when he is morally required to do so. ${ }^{10}$ That is not true of the many other people in the world who are engaged in wrongdoing of various sorts.

Of course, the arguments sketched above assume that bystanders like Abel must initially bear at least some cost to prevent harm from occurring to other innocent people.

\footnotetext{
${ }^{10}$ The same is true of Walker with respect to the child in Drowning Child - she acts culpably when failing to prevent the child's death.
} 
I assume that Frowe would agree that agents who are bystanders are required to take on at least trivial costs to save others in (emergency) situations of the sort we have been discussing. ${ }^{11}$ Abel must intervene to prevent Vicky's death if he will bear only a very trivial cost such as muddying his trousers, pressing a button, using his vocal chords, or perhaps suffering a small bruise. Many would think that the required cost would be greater still. This is entirely consistent with maintaining that the cost Abel must bear would be less than what could be required of those who, like Ollie, Ella or Dirk, do or enable harm, or prevent others from escaping it. Indeed, there is a rationale for regarding Abel as different from these others. Whereas Vicky could say of the others that she was doing just fine before they came along, she cannot say this of Abel. This is true even if Abel could have acted to avert the initiation of the threat in the first place (for example, by warning Dirk.) So giving up on the idea that bystanders cannot be responsible for threats does not mean that they lack special moral status.

Suppose that, despite being aware that he can protect Vicky at trivial cost, Abel remains unwilling to shoulder any cost to prevent harm to her. In that case, it seems plausible that cost could be permissibly imposed on him by Vicky in self-defence, or by others insofar as this was a necessary side effect of protecting Vicky. Moreover, Abel seems liable to bear this cost. If Vicky could now prevent her own death by imposing a bruised finger on Abel, she could do so without wronging him. After all, this was cost Abel was required to bear in the first place in order to protect her, and he could have protected her at much less cost even than this!

Just how much cost could Vicky impose on Abel? This would seem to depend on Abel's degree of culpability for the persistence of the threat. If his inaction resulted from the fact that he just didn't care about Vicky's plight and preferred to remain undisturbed with his picnic on the hill, he might be liable to less harm than if he actively welcomed

\footnotetext{
${ }^{11}$ Frowe's discussion of Drowning Child suggests that she affirms positive duties to rescue.
} 
Vicky's death or was disposed to bring it about in some other way had the cart not fortuitously been on track to kill her. What seems clear, however, is that Abel is liable to bear more cost than was initially required of him. Suppose that the means of protecting Vicky at trivial cost (for example, by pressing the button) during the interval between $t_{1}$ and $t_{2}$ are now no longer available. At $t_{3}$ it will now cost substantially more to save her. In this case Abel's decision not to causally interfere with the threat to Vicky during the interval $t_{1}-t_{2}$, when doing so was not at all costly, has led to a situation where someoneeither Abel or Vicky (or both in some measure)—must suffer a loss that is greater than anyone need have suffered previously. Since this increase in the cost of saving Vicky results from Abel's culpable failure to assist, it seems only fair that he rather than she should bear the cost.

\section{Killing Bystanders}

So far our discussion has focused on whether bystanders can be liable to being harmed, and whether it is permissible to harm them. But Frowe's book is concerned primarily with one very serious sort of harm to others-killing. Perhaps it remains impermissible to kill bystanders in self-defence. Or perhaps they cannot become liable to being killed, even if they can be liable to lesser harms.

Let's consider permissibility first. As we've noted, Frowe holds that we can permissibly kill innocent threats in self-defence. That is, if Dirk involuntarily initiates a threat to Vicky—he is blown into a cart, sending it downhill towards Vicky—she can permissibly kill Dirk to save herself-say as an unavoidable side-effect of preventing it from hitting her-so long as this was necessary. In this case, he would be killed permissibly, without being liable to be killed. Now imagine that Abel is also on the scene. 
Unlike Dirk, he played no role in initiating the threat. But he did have an opportunity to prevent its persistence by effortlessly pushing the fence-triggering button next to him. Vicky now has two options for protecting herself: she can kill Dirk as a side-effect of saving herself or she can kill Abel as a side-effect (she can shoot at the button in front of him, which will trigger the fence but continue on and kill Abel). I submit that if it is permissible to kill Dirk, it should also be permissible to kill Abel. After all, it is only Abel who has failed in an obligation to Vicky, and it is because of this failure that she will face her death. Dirk has done nothing with respect to the threat which he has initiated, while Abel has.

Is Abel liable to be killed? Here I think his degree of culpability is crucial. If the situation is fully transparent to him and he repeatedly refused to take on the trivial cost of preventing this very serious harm—say because he welcomes Vicky's death and would be disposed to bring it about himself_-his claim to protection is dramatically reduced. Even if we are unsure whether even very culpable bystanders are liable to be killed when the life of only one innocent person is at stake, it seems implausible that they would not be liable when many are at stake. If Abel can save the lives of 20 innocent people in the situation as described, does he really not forfeit his right against being killed insofar as this is necessary to protect the victims? Does he retain his right to defend himself against the 20 should they take defensive action against him, when his culpable failure to prevent harm is the reason why anyone must now be harmed?

Frowe worries that introducing a category of responsible bystanders will "undermine the idea that bystanders are off limits."(28) This is a reasonable concern. Note, however, that the arguments presented above only affirm that agents who very culpably fail to prevent serious harms can be liable to defensive harm. Situations are rarely so transparent to bystanders as they are in the case of Abel considered above. Moreover, the costs to bystanders of preventing harm to others are typically non-trivial. 
For these reasons, few bystanders will in practice be liable to be killed in self-defence or in defence of others. Allowing for the category of responsible bystanders does not, as Frowe suggests, mean that describing a person as a bystander lacks implications for how we are required to treat her (43). Whereas those who pose threats make people worse off than were they to be absent from the scene altogether-Vicky would be safe were Dirk, Ella, or Ollie not to be present - this is not true of bystanders. Because the presence of bystanders on the scene at which a person has been placed under threat of harm has not made that person worse off, the circumstances under which bystanders can be required to bear cost to protect those under threat are much more limited. We can only impose significant costs on bystanders to protect others under threat without wronging them if they have culpably failed to prevent the threat from coming about in the first place, or to prevent its persistence. 